Article

\title{
Design and Application of Highly Efficient Flame Retardants for Polycarbonate Combining the Advantages of Cyclotriphosphazene and Silicone Oil
}

\author{
Jicheng Jiang, Yanbin Wang *D, Zhonglin Luo, Tianyi Qi, Yihui Qiao, Menghao Zou and \\ Biaobing Wang * \\ Jiangsu Key Laboratory of Environmentally Friendly Polymeric Materials, School of Materials Science and \\ Engineering, Jiangsu Collaborative Innovation Center of Photovolatic Science and Engineering, \\ Changzhou University, Changzhou 213164, Jiangsu, China \\ * Correspondence: wangyanbin@cczu.edu.cn (Y.W.); biaobing@cczu.edu.cn (B.W.); \\ Tel.: +86-519-8633-0095 (Y.W.); +86-519-8633-0075 (B.W.)
}

Received: 17 June 2019; Accepted: 4 July 2019; Published: 5 July 2019

\begin{abstract}
A novel flame retardant (HSPCTP) was successfully designed and incorporated into a polycarbonate (PC) matrix. Combining the advantages of cyclotriphosphazene and silicone oil, PC/HSPCTP composites passed UL-94 V-0 rating testing with only $3 \mathrm{wt} \%$ HSPCTP, and their LOI value increased from $25.0 \%$ to $28.4 \%$. The findings showed that HSPCTP exhibits both gas-phase and solid-phase flame-retardant effects. Furthermore, the incorporation of HSPCTP into PC could suppress the release of smoke. Finally, the flame-retardant mechanism is discussed in depth.
\end{abstract}

Keywords: triphosphazene; flame retardant; silicone oil; polycarbonate

\section{Introduction}

Due to its strong impact resistance, heat resistance, and dimensional stability, polycarbonate (PC) has been widely used in fields such as automobiles, office equipment, packaging, construction, sports equipment and health care industries. Although pure PC resin has a certain degree of flame retardancy ( $25 \%$ of LOI value and UL-94 V-2 rating), it is still not suitable in harsh applications requiring a more stringent flame-retardant rating. Many studies have been carried out on the improvement of the flame retardancy of PC in recent decades, and various kinds of flame retardants (including halogenated organic compounds, organophosphates, and silicon-containing compounds) have been developed [1-13]. For example, halogen-containing flame retardants are known to be highly efficient for PC. However, they release toxic and corrosive substances during their decomposition and cause environmental problems. Therefore, it is necessary to develop a halogen-free and environment-friendly flame retardant to improve the flame retardancy of PC.

Cyclotriphosphazene derivatives are important types of inorganic materials containing alternate phosphorus and nitrogen atoms in their cyclic skeletons [14-16]. Moreover, hexachlorocyclotriphosphazene (HCCP) is often used as a starting material to prepare cyclotriphosphazene derivatives due to the high reactivity of the $\mathrm{Cl}$ atom. Varieties of derivatives have been synthesized by the substitution reaction of $\mathrm{Cl}$ with organic nucleophiles (alkyl- $\mathrm{CH}_{3}$, alkoxy-OCH $\mathrm{H}_{3}$, phenoxy-OPh, amine- $\mathrm{NH}_{2}$, etc.) [11,17-20]. The cyclotriphosphazene derivatives display both inorganic properties and organic properties, such as high temperature resistance, flame retardancy and self-extinguishing properties [21-24]. A phosphorus/nitrogen-containing compound based on maleimide and cyclotriphosphazene was synthesized by Yang and used as the flame retardancy for epoxy resin [25]. An LOI value of $36.5 \%$ and a UL94 V-0 rating were achieved with a high loading level of a $17 \mathrm{wt} \%$ flame retardant. 
Cao synthesized hexakis (4-nitrophenoxy) cyclotriphosphazene (HNTP) and combined it with ammonium polyphosphate to improve the intumescent flammability and thermal properties of acrylonitrile-butadiene-styrene copolymer (ABS). The LOI value of $25.6 \%$ and UL-94 V-0 rating were obtained in the case of ABS (70 wt\%) /HNTP (15wt\%) /APP (15wt\%) [26]. Notably, although the flame-retardant grade of these composites reached V-0 rating, the weight ratios of the flame retardants were too high, which worsens the mechanical performance.

On the other hand, silicon-containing compounds have been considered as a kind of high-efficient flame retardants $[27,28]$. For example, Song synthesized carboxyl-containing polysiloxane [29] and incorporated it into PC to improve the flame-retardant abilities. The LOI value of the composites was $38.5 \%$ and the sample passed UL-94 V-0 testing even when the content of flame-retardant was as low as $1.0 \mathrm{wt} \%$. Unfortunately, the use of platinum dioxide catalyst $\left(\mathrm{PtO}_{2}\right)$ increased the cost of reaction and the difficulty of post-treatment.

Therefore, it is necessary to combine the excellent flame retardancy of cyclotriphosphazene with silicone oil. However, silicon-containing cyclotriphosphazene flame retardants have scarcely been reported. He et.al [30] employed hydroxyl silicone oil to replace chlorine on HCCP (SCP), however, the chlorine was not completely replaced. Furthermore, a relatively larger amount of flame retardant $(7.5 \%)$ was required to achieve the UL94 V-0 flame-retardant rating for PC materials.

In this study, a novel silicon-containing cyclotriphosphazene compound was designed and prepared through the substitution of hexachlorocyclotriphosphazene with dihydroxypropyl silicone oil and sodium phenoxide. It was found that chlorine atoms almost disappeared. Moreover, PC material reached the UL94 V-0 flame-retardant grade, with an amount of only $3 \mathrm{wt} \%$ of flame retardant. In addition, the flame-retardant mechanism was investigated deeply by thermogravimetric analysis/infrared spectrometry (TG-IR), scanning electron microscopy (SEM), and cone calorimeter tests.

\section{Materials and Methods}

\subsection{Materials}

Hexachlorocyclotriphosphazene (HCCP) was pursed from the Zibo Blueprint Chemical Co. Ltd. (Zibo, China). Dihydroxypropyl silicone oil (WSS-140, hydroxyl value 1.5\%) was purchased from the Wushi New Material Co. Ltd. (Hangzhou, China). Phenol, Sodium (Na), Triethylamine (TEA), N-hexane, Tetrahydrofuran, Benzophenone, talcum powder, and polytetrafluoroethylene (PTFE) were purchased from the Jiangsu Qiangsheng Functional Chemical Co. Ltd. (Nantong, China). Dichloromethane was purchased from the Sinopharm Group Chemical Reagent Co. Ltd. (Shanghai, China). Polycarbonate was purchased from Bayer AG (Leverkusen, Germany).

\subsection{Synthesis of HSPCTP}

The target product (HSPCTP) was prepared according to the following two steps and the synthetic routes are shown in Scheme 1.

Firstly, $3.0 \mathrm{~g}(8.63 \mathrm{mmol})$ hexachlorocyclotriphosphazene (HCCP), $16.40 \mathrm{~g}(8.63 \mathrm{mmol})$ bihydroxypropyl silicone oil and $10 \mathrm{~mL}$ dry tetrahydrofuran (THF) were added at $25^{\circ} \mathrm{C}$ to a $250 \mathrm{~mL}$ four-necked flask equipped with a mechanical stirrer, a reflux condenser and a nitrogen inlet. Then the reaction temperature was raised to $70^{\circ} \mathrm{C}$, and $1.75 \mathrm{~g}(17.26 \mathrm{mmol})$ triethylamine was slowly added to the four-necked flask under a nitrogen atmosphere. After completion of the drop-wise addition, the reaction continued for another $24 \mathrm{~h}$ to obtain a yellow oily product, and was then filtered under reduced pressure to remove triethylamine salt. Finally, the lower liquid was separated and then the solvent was removed by rotary evaporation. An amount of $15.93 \mathrm{~g}$ HSCPT was obtained with a yield of $84.82 \%$.

Anhydrous THF $(20 \mathrm{~mL})$ and $1.19 \mathrm{~g}(51.7 \mathrm{mmol})$ of sodium swarf were placed in a three-necked flask, and $4.87 \mathrm{~g}(51.7 \mathrm{mmol})$ of phenol was slowly added at room temperature. The reaction continued for 5-6 h. The sodium phenolate solution was successfully prepared. 
The obtained intermediate product HSCPT and $10 \mathrm{~mL}$ dry THF were added to a four-necked flask equipped with a mechanical stirrer, a reflux condenser and a nitrogen inlet. After, the HSCPT was completely dissolved in dry THF and stirred. The reaction temperature was raised to $70{ }^{\circ} \mathrm{C}$ and the prepared sodium phenolate solution $(5.00 \mathrm{~g}, 43.15 \mathrm{mmol})$ was slowly added to the four-necked flask under a nitrogen atmosphere. After completion of the addition, the reaction continued for $24 \mathrm{~h}$ to obtain a pale yellow viscous liquid product. The reaction mixture was concentrated by rotary evaporation to remove excess solvent and achieve a thick liquid. Then, the liquid was dissolved with the proper amount of methylene chloride and washed with plenty of deionized water 3-4 times until the water layer became clear. Afterwards, the lower liquid was separated and the solvent was removed by rotary evaporation. The liquid product was placed in a vacuum oven at $60^{\circ} \mathrm{C}$ for $12 \mathrm{~h}$. An amount of $17.35 \mathrm{~g}$ HSPCTP was obtained, with a yield of $84.65 \%$.
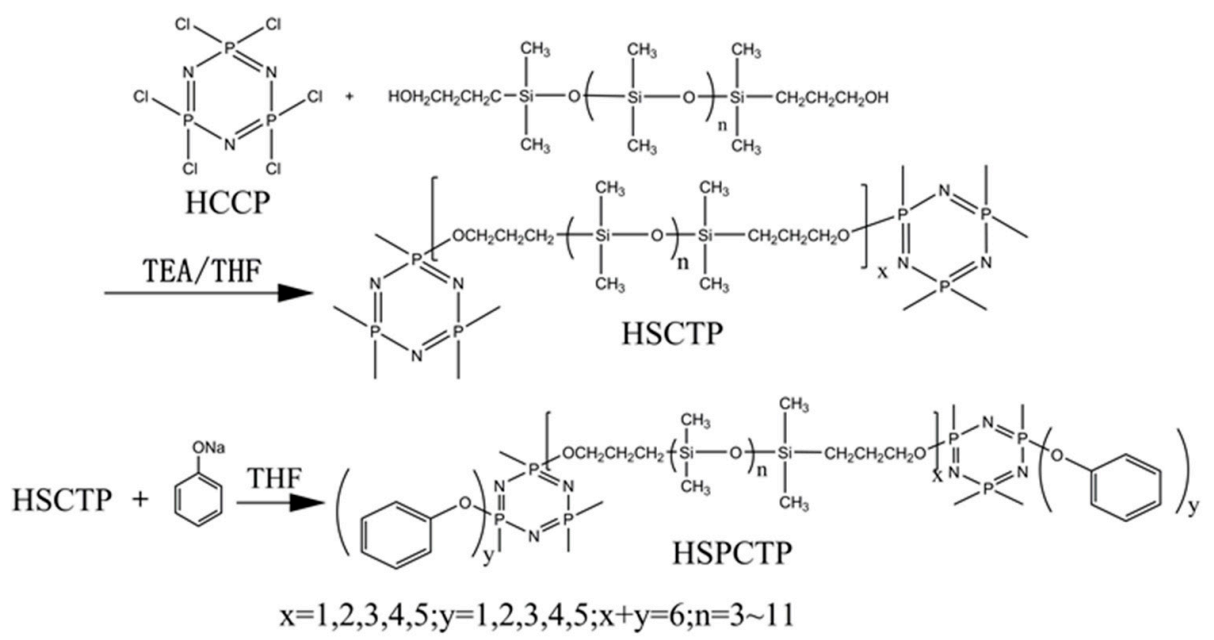

Scheme 1. The synthetic route of HSPCTP.

\subsection{Preparation of Flame-Retardant PC Composites}

A series of PC/HCPTP composites were prepared by melt blending varying contents of HCPTP from 0 to $5 \mathrm{wt} \%$. PC, talcum powder and polytetrafluoroethylene (PTFE) were placed in a vacuum oven and dried at $100{ }^{\circ} \mathrm{C}$ for $12 \mathrm{~h}$ before blending. Then, PC, talc, polytetrafluoroethylene (PTFE) and cyclotriphosphazene derivatives were added to the internal mixer and blended at $250{ }^{\circ} \mathrm{C}$ for $4 \mathrm{~min}$. Then, the mixture was poured into the prepared molds. Thereafter, all samples were cooled slowly at room temperature in order to avoid cracking, and then the performance testing was carried out.

\subsection{Characterization}

The Fourier transform infrared (FTIR) spectra were investigated by a Nicolet 6700 FTIR (Madison, WI, USA) instrument at room temperature. The samples were mixed with $\mathrm{KBr}$ pellets and scanned 32 times over a spectral range of $4000-400 \mathrm{~cm}^{-1}$ with a resolution of $4 \mathrm{~cm}^{-1}$.

The ${ }^{29} \mathrm{Si}$ NMR and ${ }^{31} \mathrm{P}$ NMR spectra were conducted on a Bruker AV II- $400 \mathrm{MHz}$ (Billerica, MA, USA) at room temperature, using DMSO-d6 as the solvent.

Elemental analysis spectra were investigated by a PerkinElmer EA 2400 II (Waltham, MA, USA) at room temperature in a vacuum environment.

To detect volatile pyrolysis products, a PerkinElmer TGA thermogravimetric analyzer was coupled to a PerkinElmer Fourier-transform infrared spectrometer (Waltham, MA, USA). Each sample was placed in an alumina crucible and heated from 50 to $700{ }^{\circ} \mathrm{C}$ at a heating rate of $20{ }^{\circ} \mathrm{C} /$ min under an $\mathrm{N}_{2}$ atmosphere. The thermogravimetric analyzer and the FTIR spectrometer were connected by quartz capillary at $230^{\circ} \mathrm{C}$.

The field-emission scanning electronic microscopy (FESEM), observed on an Hitachi SU8010 (Tokyo, Japan), was used to investigate the sectional morphology of the brittle fracture surface of 
flame-retardant PC composites and the surface of char residue of the flame-retardant PC composites after the vertical burning test was investigated by an Hitachi S3400 N (Tokyo, Japan). The surface of the particles and the char residue were sputter-coated with a conductive gold layer before observation. The EDS result of the residual char was measured by an energy-dispersive X-ray spectrometer.

Limiting oxygen indexes (LOI) were measured by an LOI analyzer (JF-3, Jiangning Co. Ltd., Nanjing, China) with sheet dimensions of $130 \mathrm{~mm} \times 6.5 \mathrm{~mm} \times 1.8 \mathrm{~mm}$, according to GB/T 2406-93 standard. The vertical burning test (UL-94) of each sample was evaluated on a CZF-5-type instrument (Shine Ray Instrument Co. Ltd., Nanjing, China) with sheet dimensions of $130 \mathrm{~mm} \times 13 \mathrm{~mm} \times 1.8 \mathrm{~mm}$ according to ASTMD3801. An average of at least five replicas was used for each sample.

The fire behavior of the flame-retardant PC composites was evaluated via a cone calorimeter device (Fire Testing Technology, East Grinstead, UK) according to ISO 5660-1. The foursquare samples with the dimension of $100 \mathrm{~mm} \times 100 \mathrm{~mm} \times 3 \mathrm{~mm}$ were exposed to a radiant cone at a heat flux of $35 \mathrm{~kW} / \mathrm{m}^{2}$. In both micro-combustion calorimetry and cone calorimetry tests, the data we obtained from the two parallel tests were close to each other $( \pm 5 \%)$.

\section{Results}

\subsection{Characterization of Chemical Structure}

\subsubsection{Fourier Transform Infrared (FTIR) Analysis}

Figure 1 illustrates the FTIR spectra of HCCP, HSCTP and HSPCTP. All the specimens observed reached a characteristic $\mathrm{P}=\mathrm{N}$ absorption peak at around $1250 \mathrm{~cm}^{-1}$, which indicates that the structure of the phosphazene ring is not destroyed after the incorporation of silicone oil and phenol. Compared with HCCP, the spectrum of HSCTP reached two new peaks at $2960 \mathrm{~cm}^{-1}$ and $1000 \sim 1130 \mathrm{~cm}^{-1}$, which belong to the $\mathrm{Si}-\mathrm{CH}_{3}$ and $\mathrm{Si}-\mathrm{O}$ bonds from dihydroxypropyl silicone oil, respectively. In other words, the silicone oil was successfully introduced into the phosphazene ring. Meanwhile, another two peaks appear at $1500 \mathrm{~cm}^{-1}$ and $970 \mathrm{~cm}^{-1}$ in the spectrum of HSCTP, which are attributed to the deforming vibration of the benzene ring skeleton and the stretching vibration of the $\mathrm{P}-\mathrm{O}-\mathrm{C}$ bond, respectively. This indicates that the partial chlorine atom in the phosphazene ring was replaced by the phenoxy group. Notably, the vibration peak $\left(600 \mathrm{~cm}^{-1}\right.$ and $\left.520 \mathrm{~cm}^{-1}\right)$ of the $\mathrm{P}-\mathrm{Cl}$ bond almost disappears in the spectrum of HSCTP, suggesting that the chlorine was almost replaced by the silicone oil and phenoxy groups. This is further confirmed by the XPS spectrum, as shown in Figure 2, and the elemental data of HSPCTP are summarized in Table 1. It is found that the weight ratio of chlorine is as low as $0.63 \mathrm{wt} \%$, which suggests that it can meet the requirements of RoHS (the Restriction of the use of certain hazardous substances in electrical and electronic equipment).

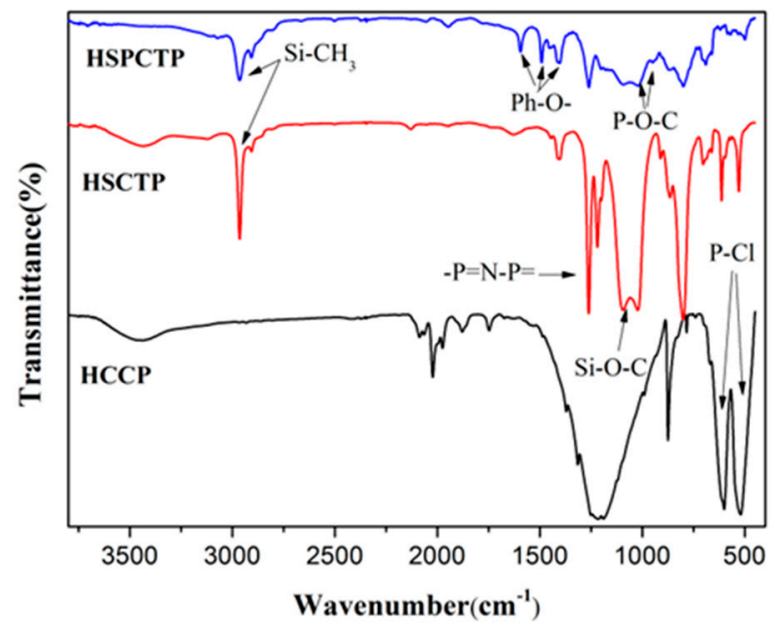

Figure 1. FTIR spectra of HCCP, HSCTP and HSPCTP. 


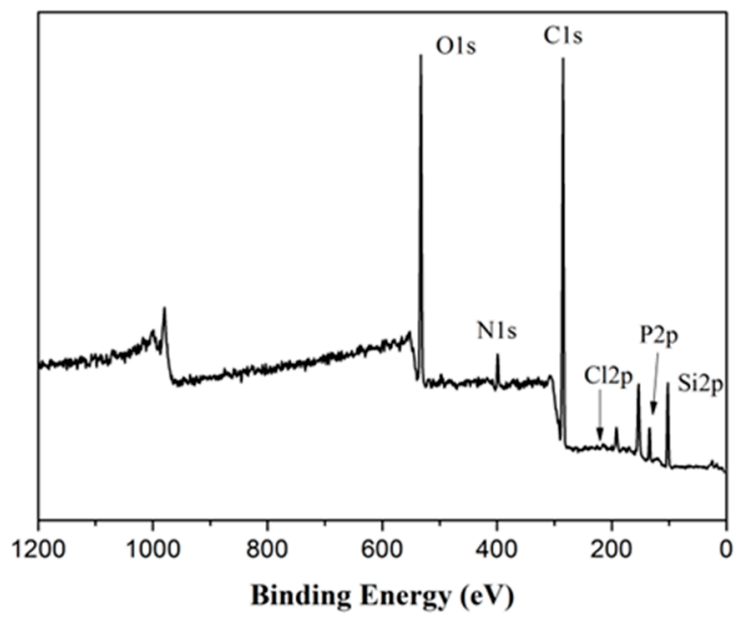

Figure 2. The XPS spectrum of the synthesized HSPCTP.

Table 1. Elemental data of HSPCTP.

\begin{tabular}{ccccc}
\hline Sample & Peak BE (eV) & Area (P) & Atom (\%) & Quality (wt \%) \\
\hline C 1s & 281.95 & $16,394.23$ & 58.49 & 44.10 \\
N 1s & 395.35 & 1459.72 & 2.93 & 2.58 \\
C1 2p & 197.65 & 179.06 & 0.28 & 0.63 \\
Si 2p & 99.1 & 3242.93 & 13.99 & 24.62 \\
P 2p & 131.14 & 1305.92 & 3.87 & 7.54 \\
O 1s & 529.59 & $16,307.59$ & 20.45 & 20.54 \\
Total & & & 100.01 & 100.01 \\
\hline
\end{tabular}

\subsubsection{Nuclear Magnetic Characterization}

The chemical structure of the target product HSPCTP was further characterized via NMR including ${ }^{31} \mathrm{P}$ and ${ }^{29} \mathrm{Si} \mathrm{NMR}$, as shown in Figures 3 and 4, respectively. For the ${ }^{31} \mathrm{P}$ NMR spectrum, the peaks at $4.90-6.40 \mathrm{ppm}$ and $8.00-10.53 \mathrm{ppm}$ correspond to the phosphorus with two dihydroxypropyl silicone oil groups and two phenoxy groups, respectively. The peak at $12.30-14.35 \mathrm{ppm}$ is attributed to the phosphorus with one phenoxy group and one dihydroxypropyl silicone oil group. In other words, the synthesized HSPCTP is a mixture of different groups. The ${ }^{29} \mathrm{Si}$ NMR spectrum shows two peaks, which correspond to two different environments of silicon in the dihydroxypropyl silicone oil. The results indicate that the groups of dihydroxypropyl silicone oil were successfully connected to the hexachlorocyclotriphosphazene.

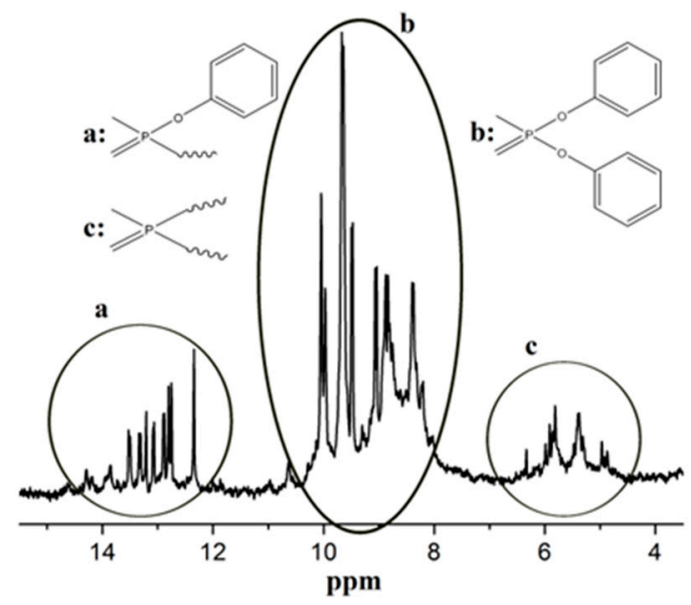

Figure 3. The ${ }^{31} \mathrm{P}$ NMR spectrum of the synthesized HSPCTP. 


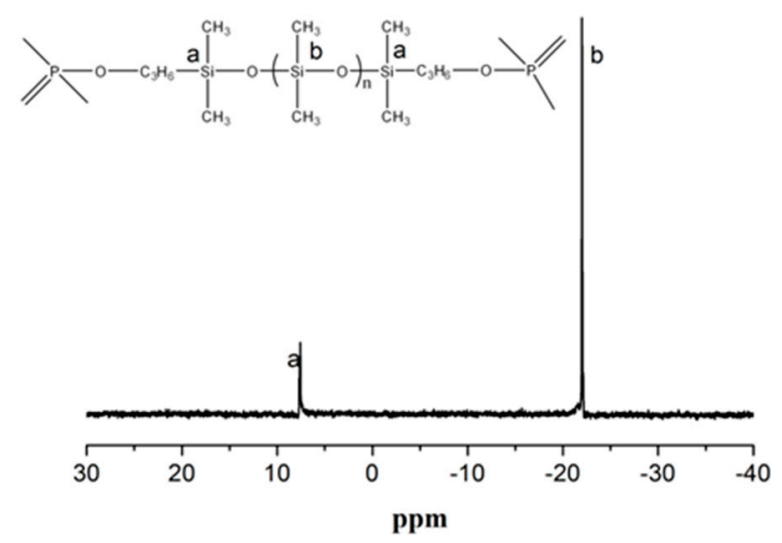

Figure 4. The ${ }^{29} \mathrm{Si}$ NMR spectrum of the synthesized HSPCTP.

\subsection{Effect of HSPCTP on the Flame Retardancy of PC-Based Blends}

The flame retardancy of pure PC and its blends were measured in terms of LOI and UL-94 testing, and the experimental data are listed in Table 2. PTFE can prevent PC melt dripping and talc can strengthen the mechanical properties of PC. Both pure PC and PC/talc/PTFE specimens give $25 \%$ of LOI value and UL-94 V-2 rating due to the serious dripping. Notably, the incorporation of HSPCTP can improve the flame retardancy of the PC-based blends. In the case of $2 \mathrm{wt} \%$ HSPCTP loading level, the PC-based blend shows $26.2 \%$ of the LOI value and UL-94 V-1 rating without dripping. Furthermore, the incorporation of $3 \mathrm{wt} \%$ HSPCTP endows the PC-based blend with $28.4 \%$ of LOI and UL-94 V-0 rating without dripping. On the other hand, we calculated the chlorine content (W) of PC/HSPCTP3 with the formula shown in Equation 1 and found that the chlorine content of PC/HSPCTP3 is 0.017\%, which is lower than that of RoHS.

$$
\mathrm{W}=\left[\frac{m_{(C l)}}{m_{(P C)}+m_{(\text {Talc })}+m_{(P T F E)}+m_{(\text {HSPCTP })}}\right] \times 100 \%
$$

Table 2. Flame retardancy of the PC/HSPCTP blends.

\begin{tabular}{cccccccc}
\hline Sample & $\begin{array}{c}\text { PC } \\
\mathbf{w t} \%\end{array}$ & $\begin{array}{c}\text { Talc } \\
\mathbf{w t} \%\end{array}$ & $\begin{array}{c}\text { PTFE } \\
\mathbf{w t} \%\end{array}$ & $\begin{array}{c}\text { HSPCTP } \\
\mathbf{w t} \%\end{array}$ & $\begin{array}{c}\text { UL-94 Rating } \\
\mathbf{( 1 . 8} \mathbf{~ m m})\end{array}$ & $\begin{array}{c}\text { Dripping } \\
\text { or Not }\end{array}$ & LOI/\% \\
\hline Pure PC & 100 & 0 & 0 & 0 & V-2 & Yes & 25 \\
PC-HSPCTP0 & 100 & 5 & 0.5 & 0 & V-2 & Yes & 25 \\
PC-HSPCTP2 & 100 & 5 & 0.5 & 2 & V-1 & No & 26.2 \\
PC-HSPCTP3 & 100 & 5 & 0.5 & 3 & V-0 & No & 28.4 \\
\hline
\end{tabular}

\subsection{Cone Calorimetry Analysis}

The cone calorimeter has been widely used to evaluate the flammability and potential fire safety of polymer materials, which can reflect the flame-retardant properties of materials precisely $[3,4]$. Table 3 presents detailed information on the combustion behavior of pure PC and PC/HSPCTP3 composites obtained from the cone calorimeter tests at a heat flux of $50 \mathrm{~kW} / \mathrm{m}^{2}$.

As shown Table 3, the time to ignition (TTI) of PC/HSPCTP3 composites decreases from 58 to $41 \mathrm{~s}$. This reveals that the flame-retardant additive of HSPCTP not only decomposes ahead of time itself, but also promotes the PC matrix to degrade at a lower temperature, which contributes to charring earlier during combustion and improves the flame retardancy of PC. This phenomenon is in agreement with others reports $[24,25,27]$.

The heat release rate (HRR) and the total heat release (THR) are important parameters to quantify the size of fire. Lower HRR and THR values show an effective flame retardancy. Figure 5 gives the HRR, the THR, the smoke produce rate (SPR) and the total smoke production (TSP) curves of pure PC and 
PC/HSPCTP3 composites. The results show that pure PC burns rapidly after ignition and the highest peak of HRR appears at $110 \mathrm{~s}$, with a peak heat release rate (PHRR) of $438.38 \mathrm{~kW} / \mathrm{m}^{2}$, as Figure $5 \mathrm{a}$ and Table 3 reveal. However, the highest HRR peak of PC/HSPCTP3 composites appears at $140 \mathrm{~s}$ with a PHRR of $245.90 \mathrm{~kW} / \mathrm{m}^{2}$, which is later and lower than that of pure PC. This may be because the HSPCTP additive decomposes and promotes the degradation and charring of the PC matrix earlier. Besides, silicon oxide derivatives and phosphoric acid derivatives are produced by decomposition of HSPCTP, which promotes decomposition of PC $[5,20,30,31]$. Figure $5 b$ and Table 3 show that the THR curve of PC/HSPCTP3 composites is lower than that of pure PC, and the THR value decreased from 71.56 to $59.11 \mathrm{MJ} / \mathrm{m}^{2}$. This is attributed to the fact that the PTFE formed a network structure after mixing and to the decomposition of HSPCTP, which contains phosphazene and hydroxypropyl silicone oil groups [32-38]. These results show that HSPCTP has a synergistic flame-retardant effect with PTFE, and that HSPCTP plays a major role in flame retardancy.
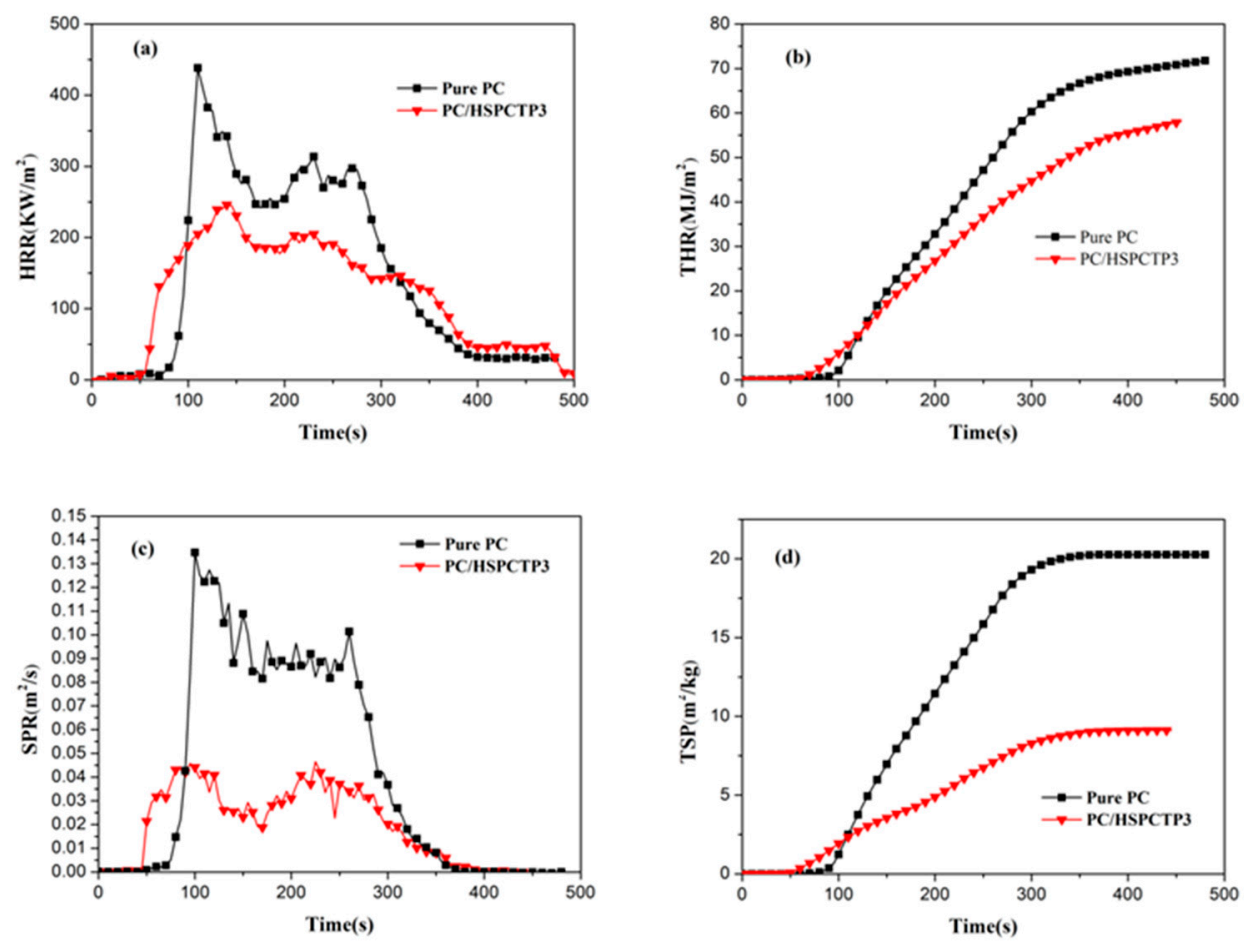

Figure 5. Heart release rate (HRR) (a), total heat release (THR) (b), smoke produce rate (SPR) (c) and total smoke production (TSP) (d) curves of pure PC and PC/HSPCTP3 composites.

Figure $5 \mathrm{c}$ and Table 3 show that the SPR curve of pure PC presents a highest peak at $105 \mathrm{~s}$ with a value of $0.135 \mathrm{~m}^{2} / \mathrm{s}$. However, the SPR curve of PC/HSPCTP 3 composites appears to peak at $49 \mathrm{~s}$, which is earlier than that of pure PC. This phenomenon indicates that HSPCTP decomposed first and produced $\mathrm{CO}_{2}$ and phosphoric acid. Besides, the SPR curve of PC/HSPCTP3 composites is lower than that of pure PC. This also indicates that HSPCTP promotes the formation of a dense carbon layer by PC, which suppresses combustion and decreases the release of a large quantity of smoke. From Figure $5 \mathrm{~d}$ and Table 3, it is evident that the TSP value of PC/HSPCTP3 is $11.57 \mathrm{~m}^{2} / \mathrm{kg}$, which is smaller than that of pure PC. This also shows that HSPCTP has a good smoke-suppressing effect on PC.

As Table 3 reveals, the average value of effective heat combustion (EHC) for PC/HSPCTP3 is $15.90 \mathrm{MJ} / \mathrm{kg}$, which is smaller than that of pure PC. This phenomenon occurs because HSPCTP contains phosphazene and dihydroxypropyl silicone oil groups, which produce noncombustible gases, such as $\mathrm{NH}_{3}, \mathrm{CO}_{2}, \mathrm{H}_{2} \mathrm{O}$ and volatile phosphide during the combustion process [32-38]. Finally, the average value of HRR for PC/HSPCTP3 is $131.93 \mathrm{~kW} / \mathrm{m}^{2}$, which is also smaller than pure PC. As discussed above, HSPCTP exhibits a high flame retardancy. 
Table 3. Cone calorimeter data for pure PC and PC/HSPCTP3 composites.

\begin{tabular}{ccc}
\hline Sample & Pure PC & PC/HSPCTP3 \\
\hline TTI $(\mathrm{s})$ & 58 & 41 \\
Peak-HRR $\left(\mathrm{kW} / \mathrm{m}^{2}\right)$ & 438.38 & 245.90 \\
$\mathrm{t}$ Peak-HRR $(\mathrm{s})$ & 110 & 140 \\
THR(MJ/m $)$ & 71.56 & 59.11 \\
Peak-SPR $\left(\mathrm{m}^{2} / \mathrm{s}\right)$ & 0.135 & 0.045 \\
$\mathrm{t}$ Peak-SPR $(\mathrm{s})$ & 105 & 98 \\
$\mathrm{TSP}\left(\mathrm{m}^{2} / \mathrm{kg}\right)$ & 20.25 & 11.57 \\
av-EHC $(\mathrm{MJ} / \mathrm{kg})$ & 23.82 & 15.90 \\
av-HRR $\left(\mathrm{kW} / \mathrm{m}^{2}\right)$ & 170.26 & 131.93 \\
\hline
\end{tabular}

\subsection{Morphology and EDS Analysis of Char Residue}

To investigate the relationship between the morphology of the char layers and the flame-retardant properties of the PC/HSPCTP composites, the char residues of the PC/HSPCTP composites are measured by SEM, as shown in Figure 6. It is evident that the outer surface of pure PC presents large holes due to insufficient char formation during combustion, as shown in Figure 6a; therefore, heat and flammable volatiles can penetrate the char layer and enter the flame zone. The inner surface has larges holes and cracks, as shown in Figure $6 \mathrm{~b}$, which lead to reduced flame retardancy. On the contrary, there is no hole observed on the outer surface of the PC/HSPCTP3 composite char layer, but there are many microspheres on the surface, as shown in Figure 6c. This is due to the decomposition of HSPCTP. These microspheres block the pores and promote the formation of a dense and regular carbon layer, which improves the flame retardancy of PC. Another reason is that the silica derivatives react with the PC chain to produce a cross-linked structure, which also promotes the formation of a compact carbon layer. In addition, phosphorus, nitrogen and benzene ring structures can also promote the formation of a regular carbon layer [16,25-30,39,40]. The inner surface, shown in Figure 6d, has more holes and microspheres. This phenomenon may be due to a large amount of inert gases, such as carbon dioxide, being decomposed by HSPCTP $[15,16,25-30,39,40]$.
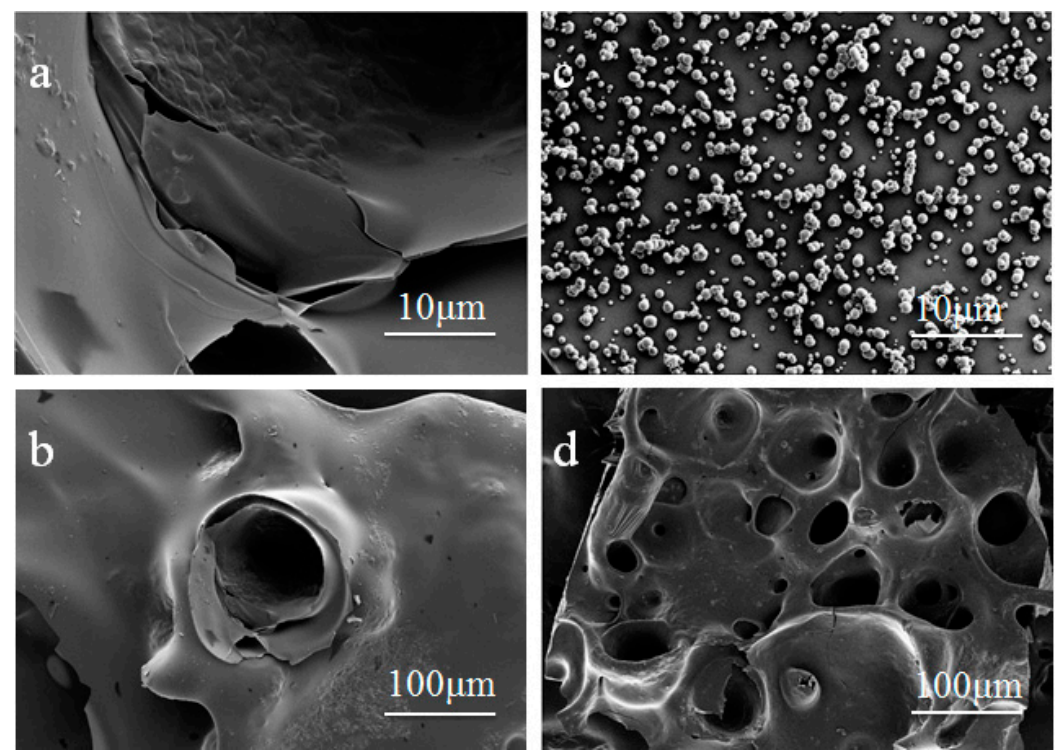

Figure 6. SEM images of the char residue of the PC/HSPCTP composites: outer surface of pure PC (a), PC/HSPCTP3 (c); inner surface of pure PC (b), PC/HSPCTP3 (d).

To further investigate the quality of the residual char, the composition of the char layer was investigated by the scanning electron microscopy/energy dispersive X-ray spectrometry (SEM/EDS). It was found that microspheres on the char surface of the PC/HSPCTP3 blend contain the elements of 
$\mathrm{C}, \mathrm{O}, \mathrm{P}$ and $\mathrm{Si}$, as shown in Figure 7a. This suggests that the microspheres may be silica microspheres, which block the pores and promote the formation of a dense and regular carbon layer. However, the non-microsphere part of the carbon layer contains the elements of $\mathrm{C}, \mathrm{O}$ and $\mathrm{Si}$, as shown in Figure $\mathrm{7b}$, which indicates that the silica derivatives react with the PC chain to produce cross-linked structures, and also promote the formation of a compact carbon layer $[15,16,25,27-30,39,40]$. Although the peak corresponding to phosphorus in Figure $7 \mathrm{~b}$ contains a small portion, it is lower than the lower limit of instrument detection.
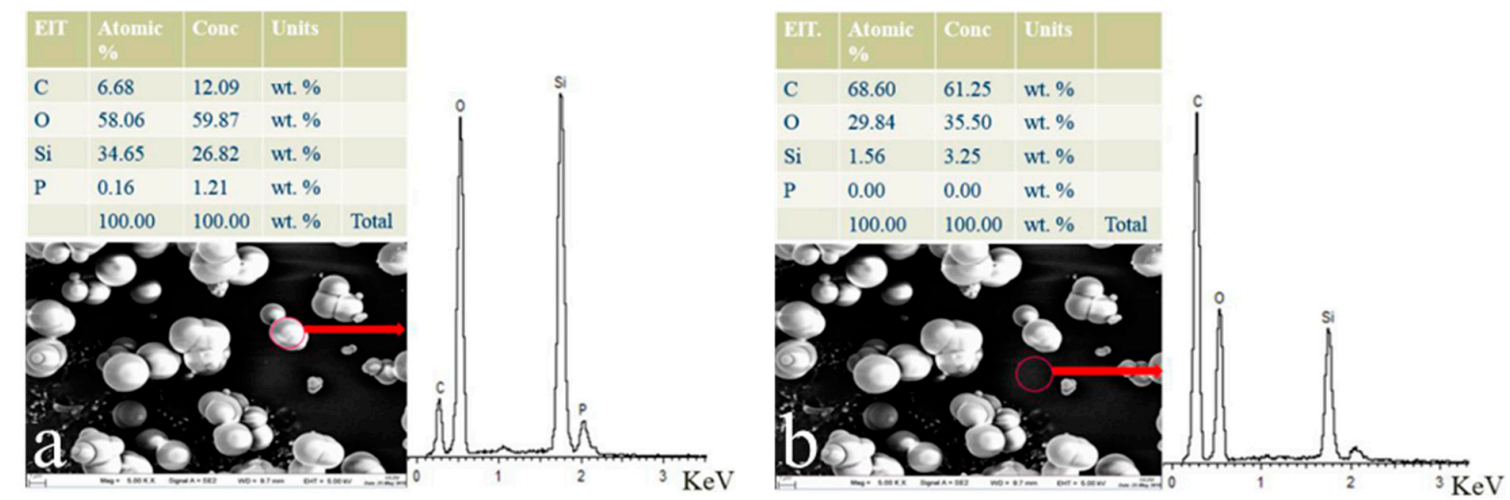

Figure 7. EDS results of the surface for PC/HSPCTP3 composites.

\subsection{FTIR Spectra of Residual Char}

In order to further investigate the formation of the intumescent char layer, the residual char of pure PC and PC/HSPCTP3 composites was examined by FTIR spectra, as revealed in Figure 8 . The peak of pure $\mathrm{PC}$ at $1761 \mathrm{~cm}^{-1}$ belongs to the ester bond (-COO-), which is a part of the PC chain structure. The multiple peaks around $760 \mathrm{~cm}^{-1}$ correspond to the characteristic of the para-substituted benzene ring. The multiple peaks around $1200 \mathrm{~cm}^{-1}$ correspond to the $\mathrm{C}-\mathrm{O}$ bonds. These prove the integrity of the PC chain structure. However, the peak of pure PC disappears at $1761 \mathrm{~cm}^{-1}$ and decreases at around $1500 \mathrm{~cm}^{-1}, 1200 \mathrm{~cm}^{-1}$ and $760 \mathrm{~cm}^{-1}$ or even disappears. This phenomenon indicates that the PC chain structure was destroyed after burning. Besides, new peaks around $3405 \mathrm{~cm}^{-1}$ and $3098 \mathrm{~cm}^{-1}$ appeared, which correspond to the hydroxyl group and the $\mathrm{C}-\mathrm{H}$ bonds on phenol, respectively. The peaks at $2873 \mathrm{~cm}^{-1}$ and $2901 \mathrm{~cm}^{-1}$ correspond to the aliphatic $\mathrm{C}-\mathrm{H}$ bonds. The peaks around $1750 \mathrm{~cm}^{-1}, 1300 \mathrm{~cm}^{-1}$ and $1100 \mathrm{~cm}^{-1}$ correspond to the aromatic ester groups. These also indicate that PC decomposes to produce small molecules after burning.

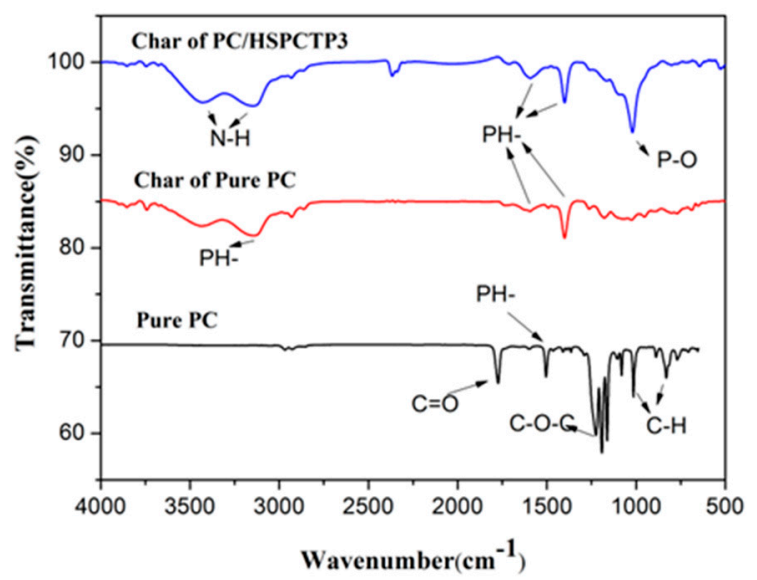

Figure 8. FTIR spectrum of the residual char of Pure PC, PC/HSPCTP3 composites obtained after the cone calorimeter test. 
Compared with pure PC, the peaks at $3405 \mathrm{~cm}^{-1}$ and $3098 \mathrm{~cm}^{-1}$ of the residual char for PC/HSPCTP3 became stronger. This was caused by the degradation of HSPCTP, which reacted with PC and produced aliphatic amines $\left(\mathrm{N}-\mathrm{H}, 3405 \mathrm{~cm}^{-1}\right)$ and aromatic amines $\left(\mathrm{N}-\mathrm{H}, 3098 \mathrm{~cm}^{-1}\right)$. The peaks at $2370 \mathrm{~cm}^{-1}$ and $2365 \mathrm{~cm}^{-1}$ belong to $\mathrm{P}-\mathrm{H}$ bonds, which indicates that compounds containing phosphorus appeared. The peaks at 1460 and $1580 \mathrm{~cm}^{-1}$ are assigned to the remaining aromatic rings after combustion $[8-16,25,27-30,39,40]$. The peak at $1196 \mathrm{~cm}^{-1}$ is attributed to the stretching vibration of $\mathrm{P}-\mathrm{N}$ bonds in phosphazene, which provides direct evidence for the phosphazene structure with excellent thermal stability existing in the residual char $[10-16,26-30,39,40]$. The peak at $1110 \mathrm{~cm}^{-1}$ is ascribed to the stretching vibration of $\mathrm{PO}_{2} / \mathrm{PO}_{3}$ in phosphate carbon complexes and aliphatic $\mathrm{Si}-\mathrm{O}-\mathrm{C}$ and $\mathrm{Si}-\mathrm{C}$ bonds, and the peak at $912 \mathrm{~cm}^{-1}$ belongs to the stretching vibration of the $\mathrm{P}-\mathrm{O}-\mathrm{P}$ bond $[39,40]$. These indicate that polyphosphoric acid and silicon-containing compounds appeared during the thermal degradation of PC. The formed acid can promote the formation of the carbonaceous char by carbonization. The silicon-containing compounds also react with the PC matrix to produce a cross-linked structure, which improves drip resistance and carbon layer formation.

\subsection{FTIR Spectra of Residual Char}

To understand the flame-retardant effect of HSPCTP on PC, the TG-IR of pure PC and PC/HSPCTP3 were investigated, as shown in Figure 9. It is clear that both the curves of pure PC and PC/HSPCTP3 show characteristic bands of water $\left(3650 \mathrm{~cm}^{-1}, 1259 \mathrm{~cm}^{-1}, \mathrm{O}-\mathrm{H}\right.$ bond) [41,42], aliphatic compounds (2972 $\left.\mathrm{cm}^{-1}, 1248 \mathrm{~cm}^{-1}, 748 \mathrm{~cm}^{-1}\right)$ [31,43], carbon dioxide (2300-2400 $\left.\mathrm{cm}^{-1}\right)$ [31,43], compounds containing aromatic rings $\left(1610 \mathrm{~cm}^{-1}, 1505 \mathrm{~cm}^{-1}\right)$ [31,43] and nitrogen compounds $\left(1200 \mathrm{~cm}^{-1}\right)$ [41]. The characteristic bands of the two samples are similar.

(a)

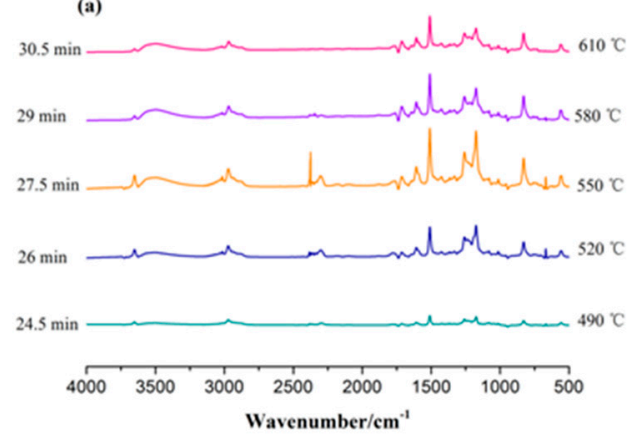

(b)

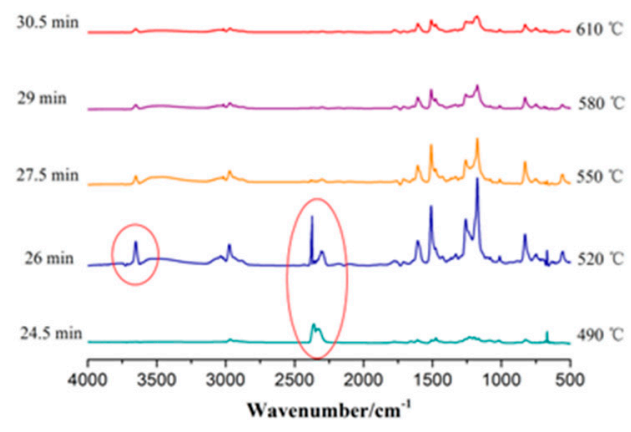

Figure 9. TG-IR spectra of pure PC (a) and PC/HSPCTP3 (b) at different decomposition temperatures.

Moreover, it is also observed that the pure PC and other composites start to produce gas products at $24.5 \mathrm{~min}$ at a temperature of $590{ }^{\circ} \mathrm{C}$. Pure PC continues to generate gas from $490{ }^{\circ} \mathrm{C}$ to $610{ }^{\circ} \mathrm{C}$. However, PC/HSPCTP3 composites release a lot of gas products at $26 \mathrm{~min}$ with the temperature at $520^{\circ} \mathrm{C}$. As the temperature increases, the amount of gas generation reduces significantly. It can be concluded that HSPCTP can promote decomposition to produce a large amount of inert gas to achieve a flame-retardant effect quickly.

\subsection{Flame-Retardant Mechanisms of PC/HSPCTP Blends}

As discussed above, HSPCTP is an efficient flame retardant for PC, which involves both a gas phase and a solid phase flame-retardant effect. As shown in Figure 10, the main degradation process is separated into three stages. In the first degradation stage, HSPCTP decomposed into silicone derivatives and a phosphazene ring-opened compound (chemical reaction 1.1). In this case, the phosphazene ring-opened compound further decomposed into phenoxy radical (PH-O-), ammonia (gas source) and metaphosphoric acid (acid source) [39,40]. Moreover, the phosphazene ring-opened compound is prone to generating phosphorus-based radicals (PO., $\mathrm{PO}_{2} \cdot$, etc.), which could manifest as 
radical scavengers to trap the $\mathrm{H}$ - and $\mathrm{HO}$ - for combustion reactions in the gas zone; it is believed that these radical scavengers are beneficial to flame retardancy [40]. With increasing temperature, the Fries rearrangement reaction of PC chains occurs (chemical reaction 1.2) [31]. This reaction can accelerate cross-linking and the carbon formation of PC.

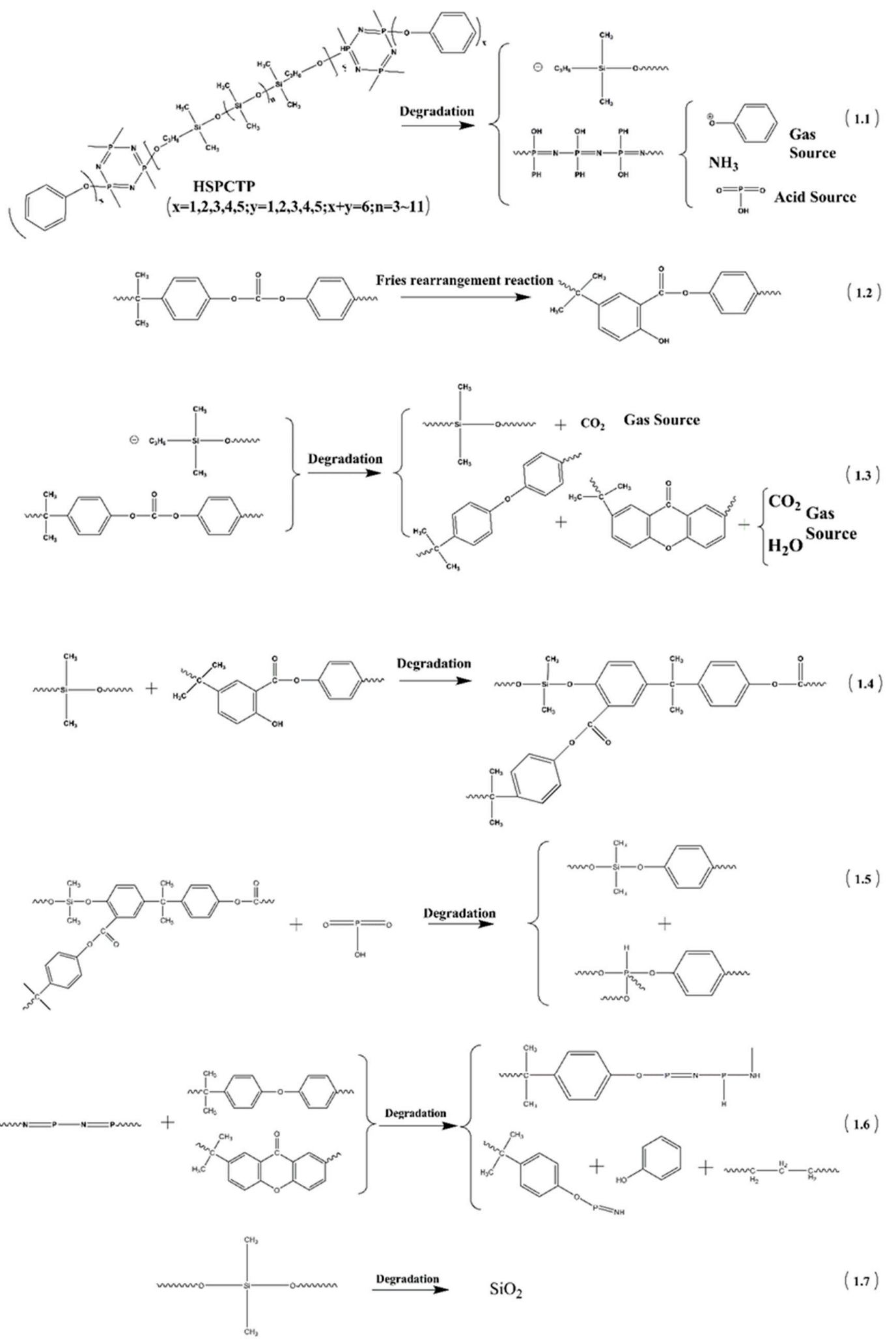

Figure 10. Schematic illustration of the flame-retardant mechanism of PC/HSPCTP composites. 
In the second degradation, the metaphosphoric acid accelerated the dehydration of PC, and the silicone derivatives decomposed into other small molecule silicone derivatives and carbon dioxide (chemical reaction 1.3) [6-15,31]. The reactions 1.1 and 1.3 produced inert gases to promote flame retardancy.

In the last stage, silicon-containing groups attacked the hydroxyl groups formed after the PC rearrangement reaction to form cross-linked carbon-forming silyl ether structures, which promoted the formation of dense, regular carbon layers (chemical reaction 1.4) [5-18,31]. The silicon-containing compounds also reacted with the PC matrix to produce a cross-linked structure, which improved drip resistance and carbon layer formation. Besides, the formed acid can react with the PC chains and promote the formation of cross-linked structures containing phosphorus (chemical reaction 1.5). Undecomposed cyclotriphosphazene reacted with short-chain molecules produced by the decomposition of PC, and then produced phenol, nitrogen-containing compounds, phosphorus-containing compounds and aliphatic compounds (chemical reaction 1.6). Some parts of silicon oil groups also turned out to be $\mathrm{SiO}_{2}$ (chemical reaction 1.7).

\section{Conclusions}

A novel flame retardant, HSPCTP, with phenoxy and hydroxypropyl silicone oil groups, was designed and incorporated into PC to improve its flame retardancy. Combining the advantages of cyclotriphosphazene and silicon compounds, PC composites passed UL-94 V-0 rating with only $3 \mathrm{wt} \%$ HSPCTP. This study found that HSPCTP stimulated PC matrix decomposition and char formation ahead of time and enhanced the char yield and the thermal stability of PC/HSPCTP composites at high temperature. Furthermore, HSPCTP also promoted the formation of a uniform, sealing, intumescent and continuous char layer with high thermal stability due to the existence of an abundant aromatic structure, phosphazene and hydroxypropyl silicone oil groups in the HSPCTP additive. The formed char layer prevented heat transmission and diffusion, limited the production of combustible gases, inhibited the emission of smoke and then led to the reduction of the heat release rate and the smoke produce rate. On the other hand, hydroxypropyl silicone oil groups generated a large amount of inert gases, such as carbon dioxide, at a high temperature, which diluted flammable and combustion-supporting gas. In other words, HSPCTP showed both gas-phase and solid-phase flame-retardation. As a result, the introduction of the prepared HSPCTP flame retardant additive to PC led to a higher flame-retardant efficiency and thermal stability.

Author Contributions: Y.W. and B.W. designed the research objective. J.J., Z.L., T.Q., Y.Q. and M.Z. performed experiments and analyzed the results. All the authors reviewed and provided feedstock on the submitted article.

Funding: This work was partly supported by the Natural Science Foundation of Jiangsu Province (BK20160280), Double Plan of Jiangsu Province.

Acknowledgments: This work was supported by the Natural Science Foundation of Jiangsu Province (BK20160280), Double Plan of Jiangsu Province, and Jiangsu Students' platform for innovation and entrepreneurship training program. We appreciate the technical assistance from the Analysis and Test Center of Changzhou University.

Conflicts of Interest: The authors declare no conflict of interest.

\section{References}

1. Ran, S.Y.; Guo, Z.H.; Chen, C.; Zhao, L.; Fang, Z. Carbon nanotube bridged cerium phenylphosphonate hybrids, fabrication, and their effects on the thermal stability and flame retardancy of the HDPE/BFR composite. J. Mater. Chem. A 2014, 2, 2999-3007. [CrossRef]

2. Qian, L.J.; Ye, L.J.; Qiu, Y.; Qu, S. Thermal degradation behavior of the compound containing phosphaphenanthrene and phosphazene groups and its flame retardant mechanism on epoxy resin. Polymer 2011, 52, 5486-5493. [CrossRef]

3. Sun, J.; Wang, X.D.; Wu, D.Z. Novel spirocyclic phosphazene-based epoxy resin for halogen-free fire resistance: Synthesis, curing behaviors, and flammability characteristics. ACS Appl. Mater. Interfaces 2012, 4, 4047-4061. [CrossRef] 
4. Yang, S.; Lv, G.; Liu, Y.; Wang, Q. Synergism of polysiloxane and zinc borate flame retardant polycarbonate. Polym. Degrad. Stab. 2013, 98, 2795-2800. [CrossRef]

5. Yang, R.; Chen, L.; Zhang, W.Q.; Chen, H.-B.; Wang, Y.-Z. In situ reinforced and flameretarded polycarbonate by a novel phosphorus-containing thermotropic liquid crystalline copolyester. Polymer 2012, 52, 4150-4157. [CrossRef]

6. Zhang, W.C.; Li, X.M.; Guo, X.Y. Pyrolysis and fire behaviour of epoxy resin composites based on a phosphorus-containing polyhedral oligomeric silsesquioxane (DOPO-POSS). Polym. Degrad. Stab. 2011, 96, 1821-1832. [CrossRef]

7. Swoboda, B.; Buonomo, S.; Leroy, E.; Lopez, C.J.M. Fire retardant poly(ethyleneterephthalate)/polycarbonate/ triphenyl phosphite blends. Polym. Degrad. Stab. 2008, 93, 910-917. [CrossRef]

8. Levchik, S.V.; Weil, E.D. Overview of recent developments in the flame retardancy of polycarbonates. Polym. Int. 2005, 54, 981-998. [CrossRef]

9. Liu, S.; Ye, H.; Zhou, Y.; He, J.; Jiang, Z.; Zhao, J.; Huang, X. Study on flame-retardant mechanism of polycarbonate containing sulfonate- silsesquioxane-fluoro retardants by TGA and FTIR. Polym. Degrad. Stab. 2006, 91, 1808-1814. [CrossRef]

10. Zhou, W.J.; Yang, H.; Zhou, J. The thermal degradation of bisphenol: A polycarbonate containing methylphenylesilicone additive. J. Anal. Appl. Pyrol. 2007, 78, 413-418. [CrossRef]

11. Zaikov, G.E.; Lomakin, S.M. Polymer flame retardancy: A new approach. J. Appl. Polym. Sci. 1998, 68, 715-725. [CrossRef]

12. Lu, S.Y.; Hamerton, I. Recent developments in the chemistry of halogen-free flame retardant polymers. Prog. Polym. Sci. 2002, 27, 1661-1712. [CrossRef]

13. Yuan, D.; Yin, H.; Cai, X. Effect of a novel flame retardant containing silicon and nitrogen on the thermal stability and flame retardancy of polycarbonate. J. Therm. Anal. Calorim. 2013, 111, 1531-1537. [CrossRef]

14. Wu, K.; Zhang, Y.; Zhang, K.; Shen, M.; Hu, Y. Effect of microencapsulation on thermal properties and flammability performance of epoxy composite. J. Anal. Appl. Pyrol. 2012, 94, 196-201. [CrossRef]

15. Gu, X.; Wei, H.; Huang, X.; Tang, X. Synthesis and characterization of a novel curing agent for epoxy resin based on phosphazene derivatives. J. Macromol. Sci. A 2010, 47, 828-832. [CrossRef]

16. Salmeia, K.A.; Fage, J.; Liang, S.; Gaan, S. An overview of mode of action and analytical methods for evaluation of gas phase activities of flame retardants. Polymers 2015, 7, 504-526. [CrossRef]

17. Muraki, T.; Ueta, M.; Ihara, E.; Inoue, K. Enhancement of thermal stability of polystyrene and poly (methyl methacrylate) by cyclotriphosphazene derivatives. Polym. Degrad. Stab. 2004, 84, 87-93. [CrossRef]

18. Liu, J.; Tang, J.; Wang, X.; Wu, D. Synthesis, characterization and curing properties of a novel cyclolinearphosphazene-based epoxy resin for halogen-free flame retardancy and high performance. RSC Adv. 2012, 2, 5789-5799. [CrossRef]

19. Liu, H.; Wang, X.; Wu, D. Novel cyclotriphosphazene-based epoxy compound and its application in halogen-free epoxy thermosetting systems: Synthesis, curing behaviors, and flame retardancy. Polym. Degrad. Stab. 2014, 103, 96-112. [CrossRef]

20. Zhang, X.; Zhong, Y.; Mao, Z. The flame retardancy and thermal stability properties of poly (ethylene terephthalate)/heakis (4-nitrophenoxy) cyclotriphosphazene systems. Polym. Degrad. Stab. 2012, 97, 1504-1510. [CrossRef]

21. Chen, S.; Zheng, Q.; Ye, G.; Zheng, G. Fire-retardant properties of the viscose rayon containing alkoxycyclotriphosphazene. J. Appl. Polym. Sci. 2006, 102, 698-702. [CrossRef]

22. Conner, D.A.; Welna, D.T.; Chang, Y.; Allcock, H.R. Influence of terminal phenyl groups on the side chains of phosphazene polymers: Structure-property relationships and polymer electrolyte behavior. Macromolecules 2007, 40, 322-328. [CrossRef]

23. Yuan, W.Z.; Tang, X.Z.; Huang, X.B.; Zheng, S. Synthesis, characterization and thermal properties of hexaarmed star-shaped poly ( $\varepsilon$-caprolactone)-b-poly (d,l-lactide-co-glycolide) initiated with hydroxyl-terminated cyclotriphosphazene. Polymer 2005, 46, 1701-1707. [CrossRef]

24. Yang, S.; Wang, J.; Huo, S.Q.; Wang, J. Synthesis of a phosphorus/nitrogen- containing compound based on maleimide and cyclotriphosphazene and its flame-retardant mechanism on epoxy resin. Polym. Degrad. Stab. 2016, 126, 9-16. [CrossRef] 
25. Cao, X.; Yang, Y.; Luo, H.; Cai, X. High efficiency intumescent flame retardancy between hexakis (4-nitrophenoxy) cyclotriphosphazene and ammonium polyphosphate on ABS. Polym. Degrad. Stab. 2017, 143, 259-265. [CrossRef]

26. Xu, G.; Xu, M.; Li, B. Synthesis and characterization of a novel epoxy resin based on cyclotriphosphazene and its thermal degradation and flammability performance. Polym. Degrad. Stab. 2014, 109, 240-248. [CrossRef]

27. Hamdani, S.; Longuet, C.; Perrin, D.; Lopez-cuesta, J.M.; Ganachaud, F. Flame retardancy of sili-cone-based materials. Polym. Degrad. Stab. 2009, 94, 465-495. [CrossRef]

28. Ebdon, J.R.; Hunt, B.J.; Joseph, P. Thermal degradation and flammability characteristics of some polystyrenes and poly (methylmethacrylate) chemically modified with silicon-containing groups. Polym. Degrad. Stab. 2004, 83, 181-185. [CrossRef]

29. Song, R.J.; Chang, L.Y.; Li, B. Flame retardancy and thermal properties of carboxyl-containing polysiloxane derivatives in polycarbonate. J. Appl. Polym. Sci. 2013, 131, 1791-1799. [CrossRef]

30. Chen, C.H.; Chiang, C.L. Preparation and characteristics of a environmentally friendly hyperbranched flame-retardant polyurethane hybrid containing nitrogen, phosphorus, and silicon. Polymers 2019, 11, 720. [CrossRef]

31. Tai, Q.L.; Yuen, R.K.K.; Yang, W.; Qiao, Z.; Song, L.; Hu, Y. Iron-montmorillonite and zinc borate as synergistic agents in flame-retardant glass fiber reinforced polyamide 6 composites in combination with melamine polyphosphate. Compos. Part A 2012, 43, 415-422. [CrossRef]

32. Pramoda, K.P.; Liu, T.X.; Liu, Z.H.; He, C.; Sue, H.J. Thermal degradation behavior of polyamide 6/clay nanocomposites. Polym. Degrad. Stab. 2003, 81, 47-56. [CrossRef]

33. Yang, C.W.; Liang, G.Z.; Gu, A.J.; Yuan, L. Flame retardancy and mechanism of bismaleimide resins based on a unique inorganic-organic hybridized intumescent flame retardant. Ind. Eng. Chem. Res. 2013, 52, 15075-15087. [CrossRef]

34. Xu, T.; Huang, X.M. A TG-FTIR investigation into smoke suppression mechanism of magnesium hydroxide in asphalt combustion process. J. Anal. Appl. Pyrol. 2010, 87, 217-223. [CrossRef]

35. Pawlowski, K.H.; Schartel, B. Flame retardancy mechanisms of triphenyl phosphate, resorcinol bis (diphenyl phosphate) and bisphenol A bis (diphenyl phosphate) in polycarbonate/acrylonitrile-butadiene-styrene blends. Polym. Int. 2007, 56, 1404-1414. [CrossRef]

36. Zhang, Z.L.; Li, D.L.; Xu, W.C.; Fu, Y.B. Retardant properties of nanosilica/ptfe nanoparticals-reinforced polypropylene. Adv. Mater. Technol. 2014, 1004, 77-84. [CrossRef]

37. Chen, X.L.; Jiao, C.M. Synergistic effects of hydroxy silicone oil on intumescent flame retardant polypropylene system. J. Polym. Res. 2009, 16, 537-543. [CrossRef]

38. Niemczyk, A.; Dziubek, K.; Majewska, B.S.; Czaja, K.; Polak, J.C.; Oliwa, R.; Lenza, J.; Szołyga, M. Thermal stability and flame retardancy of polypropylene composites containing siloxane-silsesquioxane resins. Polymers 2018, 10, 1019. [CrossRef]

39. Hu, Z.; Chen, L.; Zhao, B.; Luo, Y.; Wang, D.; Wang, Y. A novel efficient halogen-free flame retardant system for polycarbonate. Polym. Degrad. Stab. 2010, 96,1-8. [CrossRef]

40. Ye, J.H.; Liang, G.Z.; Gu, A.J.; Zhang, Z.; Han, J.; Yuan, L. Novel phosphorus-containing hyperbranched polysiloxane and its high performance flame retardant cyanate ester resins. Polym. Degrad. Stab. 2013, 98, 597-608. [CrossRef]

41. Bao, C.L.; Guo, Y.Q.; Song, L.; Kan, Y.; Qian, X.; Hu, Y. In situ preparation of functionalized graphene oxide-epoxy nanocomposites with effective reinforcements. J. Mater. Chem. 2011, 21, 13290-13298. [CrossRef]

42. Li, D.; Qin, Q.; Duan, X.C.; Yang, J.; Guo, W.; Zheng, W. General one-pot template-free hydrothermal method to metal oxide hollow spheres and their photocatalytic activities and lithium storage properties. ACS Appl. Mater. Interfaces 2013, 5, 9095-9100. [CrossRef]

43. Tawiah, B.; Yu, B.; Fei, B. Advances in flame retardant poly (lactic acid). Polymers 2018, 10, 876. [CrossRef]

(C) 2019 by the authors. Licensee MDPI, Basel, Switzerland. This article is an open access article distributed under the terms and conditions of the Creative Commons Attribution (CC BY) license (http://creativecommons.org/licenses/by/4.0/). 